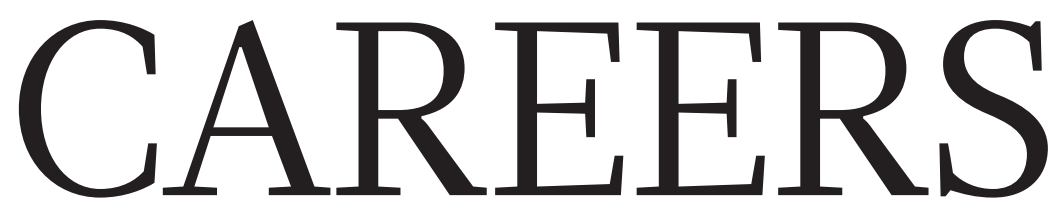

ONLINE Career resources from our scientific community at nature.com/careers
GOT A STORY? Contact us at naturecareerseditor@nature.com
INSTAGRAM Follow us at instagram.com/naturejobs

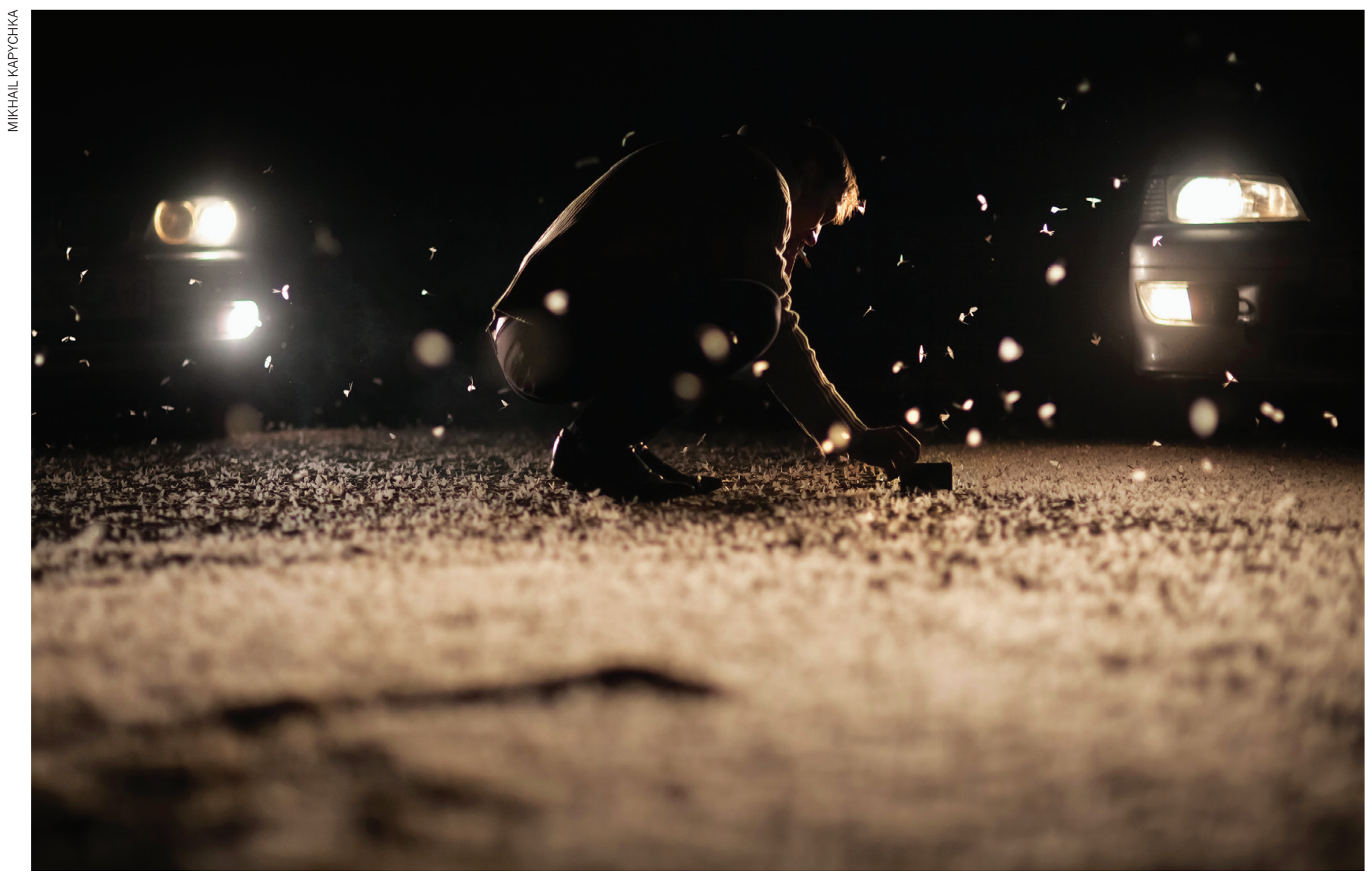

Mayflies sink to the road in Mogilev, Belarus, as they die at the end of their one-day lifespan.

\title{
PHOTOGRAPHY CONTEST
}

\section{Researchers under the lens}

\section{Announcing the winner and runners-up of Nature's annual \#ScientistAtWork photo contest.}

\section{BY JACK LEEMING}

$\mathrm{M}$ illions of mayflies emerged from the Dnieper River in Mogilev, eastern Belarus, on 18 July 2013. It was the perfect day for the naiads to hatch: warm and windless. But as the Sun set, many of the insects sank to the hot tarmac of Chelyuskintsev Street, which runs along the river before cutting through the centre of Mogilev. The mayflies, which should have remained at the river to spawn, might have mistaken the road's curvature and darkness for that of the Dnieper.

That's when Mikhail Kapychka, a history teacher and social worker from Mogilev, took the image that won Nature's third annual \#ScientistAtWork photography competition. It depicts a biologist from Mogilev State A. Kuleshov University, who is taking photographs of the mayflies as they lie dying on the road. The insects typically have a lifespan of one day. The mass-hatching phenomenon occurs every year in Mogilev.

This year's competition drew some 370 entries from around the world. We see scientists tend to a seal in the Antarctic, pose in a grotto of handwritten notes in Beijing and play

\section{DNATURE.COM}

Read the story online to see more photos:

go.nature.

com/2k2cvzp the part of resting post for a woolly monkey in Brazil. Nature's art editors selected the winning entry and runners-up on the basis of visual impact. The photographers who captured those images will receive a year's personal subscription to Nature; winner Kapychka will also receive a cash prize.

Kapychka says that residents in Mogilev contacted their local university when they realized that the mayflies' usual trajectory had been disrupted. "The light of the night city disoriented many mayflies, and they flew away from the river and so could not put their future offspring into the water," he told Nature. "It seemed to me that scientists were very tired that day." 


\section{CAREERS}

\section{Here are the rest of the winning images from the competition.}

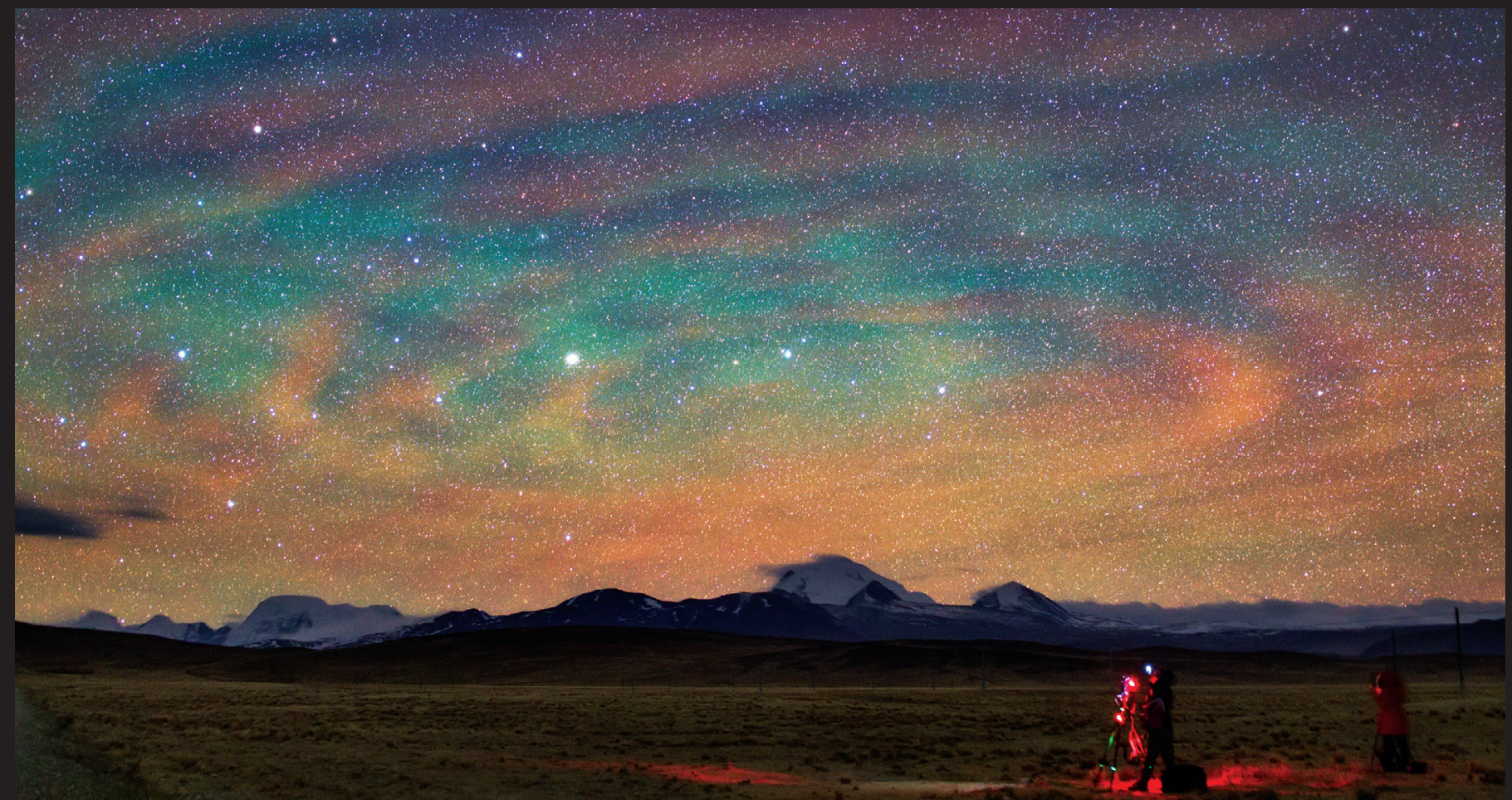

\section{GLOWING AIR (JEFF DAI)}

Swirls of aqua and peach command a starry night sky in the Xigazê region of Tibet in April 2014.

Researchers from the National Astronomical Observatories of China in Beijing and the University of Virginia in Charlottesville are observing colourful ripples of airglow. To get the photo, Jeff Dai - then an engineer on a photography holiday and now a full-time photographer — ran a long exposure of 47 seconds.

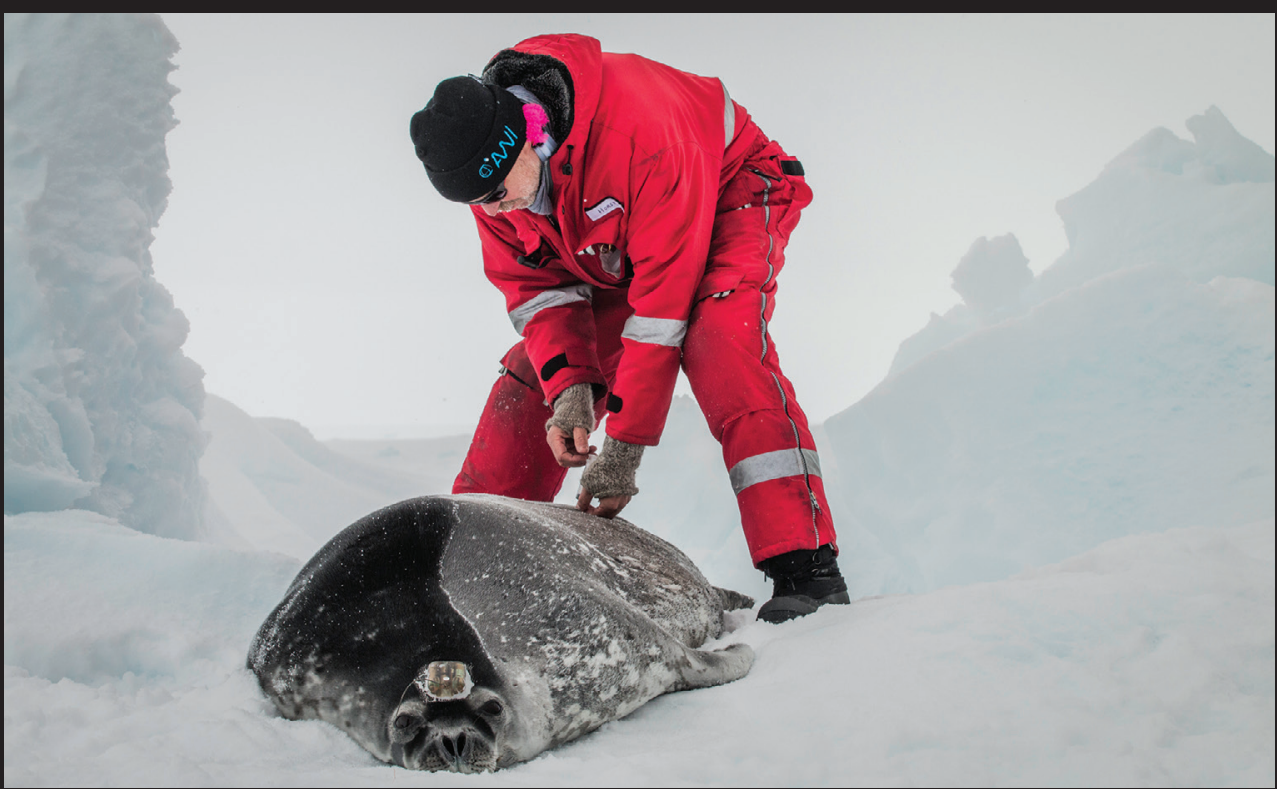

\section{SEAL THE DEAL (MIA WEGE)}

Horst Bornemann, an ecologist at the Alfred Wegener Institute in Bremerhaven, Germany, injects a female Weddell seal (Leptonychotes weddellii) with a drug to reverse the effects of an anaesthetic dart on a visit to the Ronne ice shelf in the Weddell Sea, Antarctica, in February 2018. Bornemann, who keeps a spare, brightly coloured anaesthetic dart in his hat, has just finished attaching a satellite tracker to the seal, which will record data on sea temperature and the animal's movements. Photographer Mia Wege is a postdoctoral researcher at the Mammal Research Institute at the University of Pretoria, South Africa. 


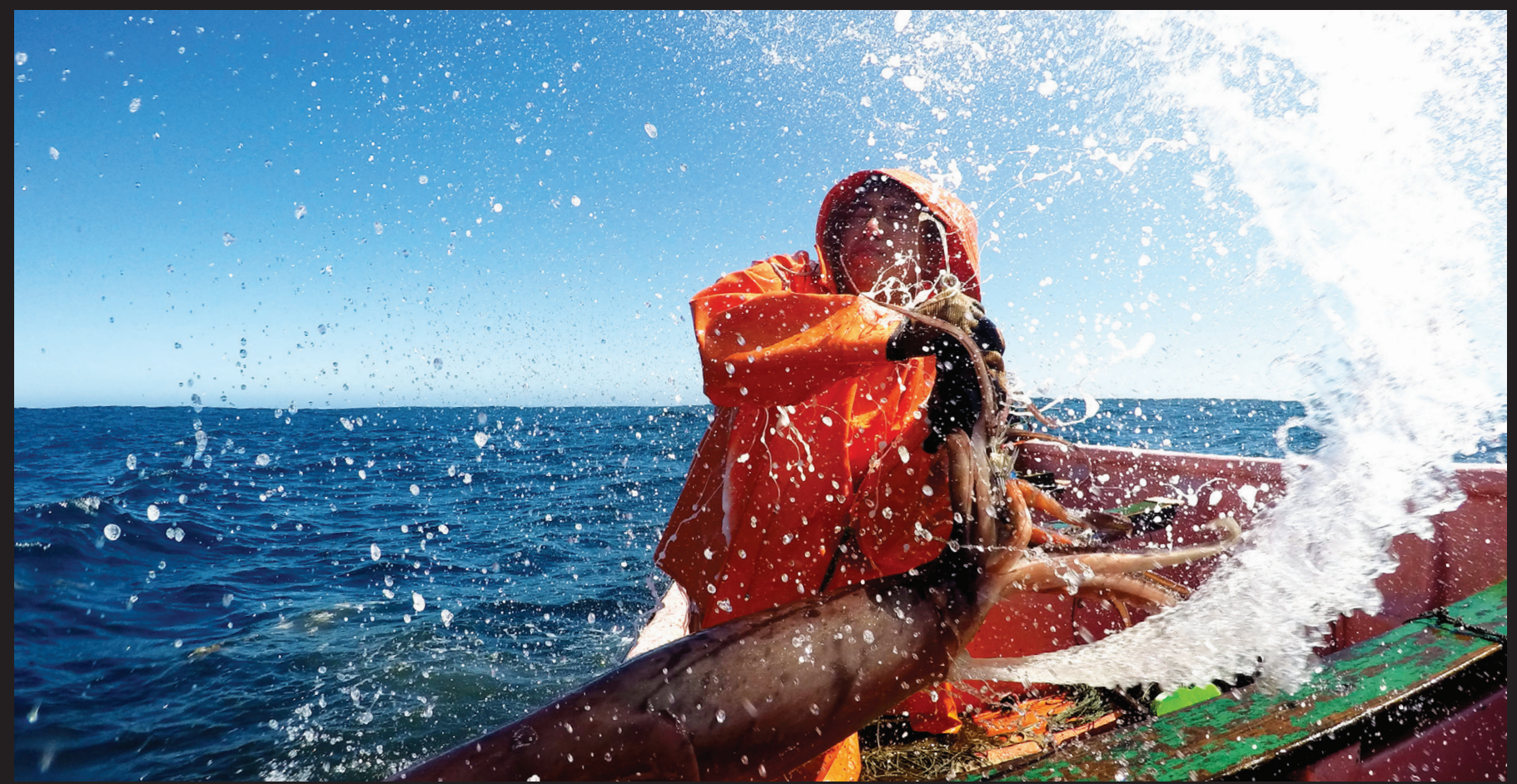

\section{SPARKLING SQUID (RODRIGO OYANEDEL)}

A champagne-like eruption of seawater splashes a fisherman as he hauls a jumbo squid (Dosidicus gigas) into his boat by hand, some 10 kilometres off the coast of Chile in January 2016. Photographer Rodrigo Oyanedel, a PhD student in zoology at the University of Oxford, UK, is conducting research on traditional sustainable fishing methods. He says that fishers such as the individual he photographed are the world's "last wild hunters".
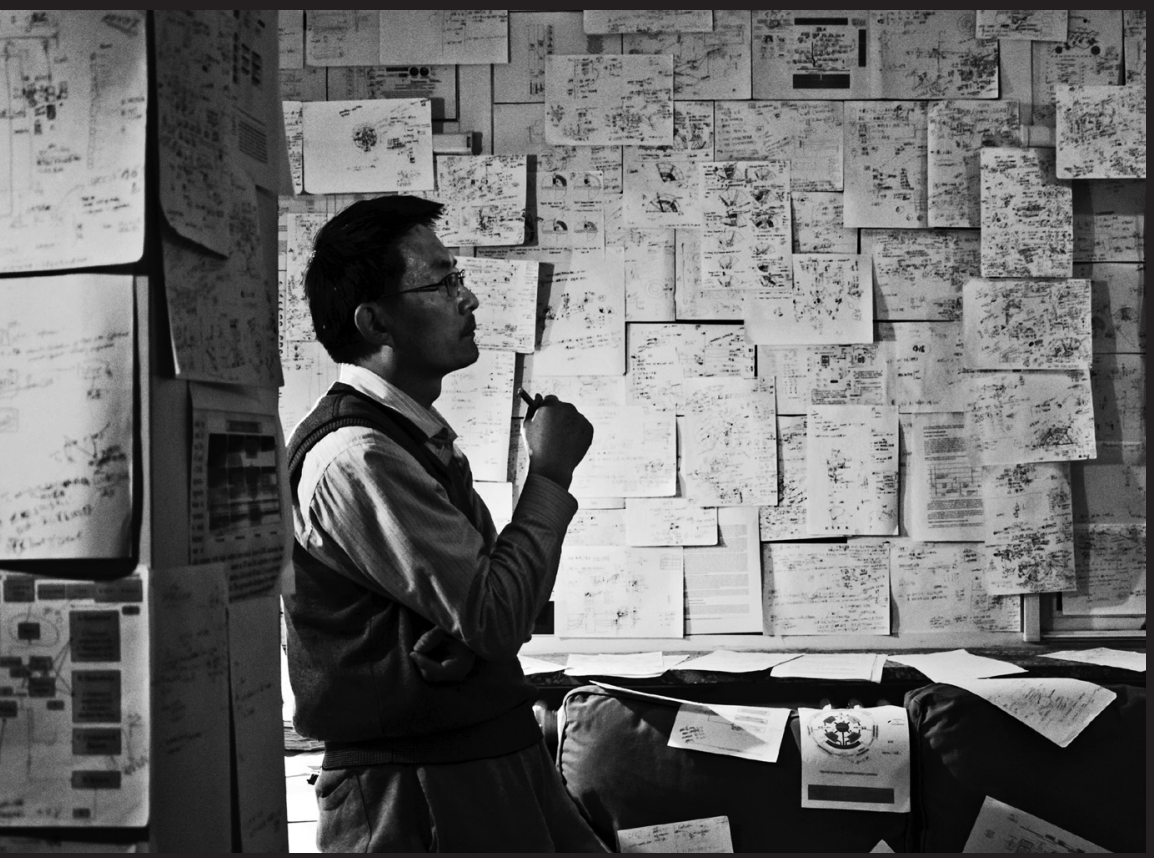

\section{DATA DRIVEN (NAN LI)}

Interior designer Nan Li snapped this contemplative portrait of her husband, Zhen Wang, a climate scientist at Beijing Forestry University, as he studied climatechange data in his office in March 2019. Li embellished the scene, but not by much: attaching detailed handwritten notes to the walls of his office is a regular habit of Wang's.

\section{DON'T MONKEY AROUND (BÁRBARA CARTAGENA MATOS)}

You can stare right back at Carlinha, a woolly monkey (Lagothrix lagotricha cana) from the Amazon Ecopark Jungle Lodge near Manaus, Brazil, as she poses in 2013 with Bárbara Cartagena Matos, now a PhD student in wildlife ecology at the University of Lisbon.

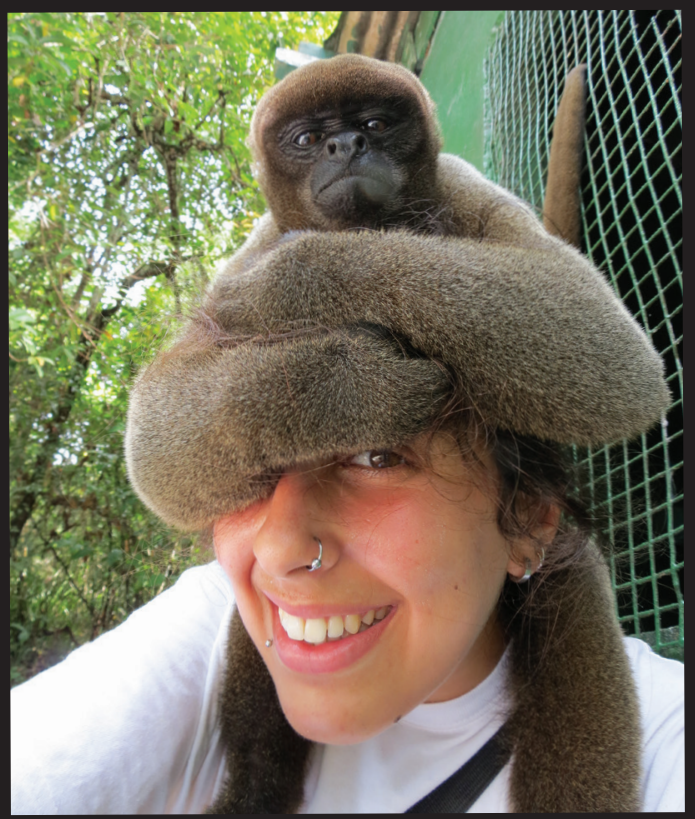

